\title{
KLF9 Is a Prognostic Indicator in Human Pancreatic Ductal Adenocarcinoma
}

\author{
ZHENGFA MAO $^{1,2}$, XIN FAN $^{1}$, JIANXIN ZHANG ${ }^{1}$, XUQING WANG $^{1}$, XIAOYAN MA $^{3}$, \\ CHRISTOPH W. MICHALSKI ${ }^{2}$ and YONG ZHANG ${ }^{1}$ \\ Departments of ${ }^{1}$ General Surgery, and ${ }^{3}$ Gynecology and Obstetrics, \\ Affiliated Hospital of Jiangsu University, Zhenjiang, P.R. China; \\ ${ }^{2}$ Department of General Surgery, University of Heidelberg, Heidelberg, Germany
}

\begin{abstract}
Background: The aim of this study was to investigate the expression of Krüppel-like factor 9 (KLF9) and its clinicopathological significance and prognostic value in pancreatic ductal adenocarcinoma. Patients and Methods: A total of 149 patients diagnosed with pancreatic ductal adenocarcinoma who underwent curative surgery were enrolled in this study. The expression of KLF9 was examined immunohistochemically. The correlation of KLF9 with clinicopathological parameters and overall survival rate of patients were analyzed. Results: Low expression of KLF9 was observed in $62.82 \%$ of tumors, which was related to poor differentiation $(p=0.036)$ and vascular invasion $(p=0.017)$. Furthermore, the overall survival of patients with low KLF9 expression was significantly shorter than that of those with high KLF9 expression $(p=0.001)$. Multivariate analysis confirmed KLF9 as an independent prognostic factor $(p=0.000)$. Conclusion: KLF9 expression was found to be a valuable prognostic factor for patients with pancreatic ductal adenocarcinoma.
\end{abstract}

Pancreatic ductal adenocarcinoma (PDAC) is the one of the main causes of cancer-related mortality in the world (1). It is a most lethal disease with a poor prognosis, an overall 5-year survival rate of $<1 \%$, and the median survival time after diagnosis is about 6 months (2). At the time of diagnosis, approximately $75 \%$ of patients with PDAC have unresectable tumors, and conventional therapies such as chemotherapy and

Correspondence to: Yong Zhang, Ph.D, Department of General Surgery, the Affiliated Hospital of Jiangsu University, 438 Jiefang Road, Zhenjiang, Jiangsu 212001, P.R. China. Tel: +86 051185082215 , Fax:+86051185026387, e-mail: 89092246@qq.com or Christoph W. Michalski, MD, Department of Surgery, Heidelberg University Hospital, Im Neuenheimer Feld 110, 69120 Heidelberg, Germany. Tel: +4962215634724, e-mail: christoph.michalski@med.uni-heidelberg.de

Key Words: Pancreatic ductal adenocarcinoma, KLF9, prognosis. radiotherapy are virtually ineffective. Increasing our understanding of the molecular mechanism of PDAC carcinogenesis is the only strategy to find new markers for early diagnosis and identifying potential targets for therapeutic intervention. Therefore, recent research has concentrated on the molecular alterations occurring in PDAC. New treatment regimens based on molecular classifications of individual tumors may provide improvements in outcome for patients with pancreatic carcinoma.

Krüppel-like factor 9 (KLF9), belongs to the mammalian Sp1/KLF family of transcription factors, which consists of 17 members (3). The members of this family are characterized by the presence of $\mathrm{Cys}_{2} / \mathrm{His}_{2}$ zinc finger motifs in the carboxyl terminus domains, binding to the GC/GT-rich box in gene promoter and enhancer regions. The $N$-terminal domains of these proteins are quite variable and are associated with different biological functions. KLF9 is involved in various biological processes such as differentiation, proliferation, and development (4-5). KLF9 was found to inhibit breast cancer invasion and is considered a tumor suppressor (6). It has also has been reported that KLF9 was down-regulated in human colorectal tumors, breast cancer and hepatocellular cancer and the reduction of KLF9 expression is associated with tumor initiation, apoptosis resistance, invasion and migration (6-8). Notably, KLF9 has been identified as having a special role in cancer stem cells, being down-regulated in ovarian cancer stem cell and glioblastoma-derived neurospheres $(4,9)$.

The evidence for an important role of KLF9 protein in tumor progression prompted us to investigate the relationship between KLF9 expression and patient prognosis in PDAC.

\section{Patients and Methods}

Patients and histological evaluation. In all, 149 patients who underwent surgery at Affiliated Hospital of Jiangsu University from 2005 to 2015 were included in this study. No patient had received any presurgical treatment, such as chemotherapy or radiotherapy. Clinical and histopathological data for these patients were extracted 
from electronic medical records. Follow-up began on the date of surgery and ended in October 2015.

Immunohistochemistry. Immunohistochemical analysis was performed on tissue microarray of specimens from 149 patients with PDAC. Formalin-fixed paraffin- embedded tissue sections $(4 \mu \mathrm{m}-$ thick) were stained using the immunoperoxidase method with avidin-biotin complex as described previously (10). The monoclonal antibody to KLF9 was from Santa Cruz Biotechnology (Santa Cruz, CA, USA). Sections were incubated with the antiKLF9 at 1:500 dilution overnight at $4^{\circ} \mathrm{C}$. The absence of nonspecific staining was confirmed by omitting the primary antibody. Labeling for marker was carried out using the Envision Plus Detection Kit (DAKO, Carpinteria, CA, USA) following the manufacturer's protocol. Nuclei were counterstained with hematoxylin. Immunohistochemical results were judged by three pathologists who were unaware of the clinical data. The staining results were judged by German semiquantitative scoring system which considers both the staining intensity and the extent of staining; the definition of low and high expression was as previously described (11).

PDACs were staged using the American Joint Committee on Cancer (AJCC) TNM staging system (12). The degree of cancer differentiation was assessed using criteria established by the World Health Organization (13). The study was approved by The Committee of Ethics in Affiliated Hospital of Jiangsu University[Aprroval number:JDFY20140526004] and informed consent was obtained for every specimen examined.

Statistical analysis. Statistical analysis of correlation between KLF9 expression and clinical parameters was performed using chi-squared test. The overall survival (OS) was estimated using the KaplanMeier method from the date of surgery.Univariate analysis of the clinicopathological variables was performed using the log-rank test. Multivariate regression was performed using the Cox proportional hazards model. All analyses were performed using SPSS statistical software (version 16.0 for windows; SPSS Inc., Chicago, IL, USA). All $p$-values were derived from two-tailed tests and $p<0.05$ was considered statistically significant.

\section{Results}

Patient population. One hundred and forty-nine patients, including 86 men and 63 women, were included in the final analysis. Their average age was 60.56 years (range $=34-80$ years). All the patients underwent pancreaticoduodenectomy with Whipple's operation $(n=112)$ or distal pancreatectomy $(n=37)$. Most tumors $(70.47 \%$ were moderately differentiated, and perineural invasion was observed in most $(75.17 \%)$ (Table I).

Tissue microarray was available for all 149 patients. A total of 38 patients were excluded from the survival analysis due to lack of follow-up; consequently 111 patients were included in the survival analysis.

Expression of KLF9 in PDAC. KLF9 staining was observed predominantly in the nucleus of tumor cells. Immunohistochemical analysis of samples showed that high KLF9 expression was found in 57 tumors $(38.26 \%)$ and low KLF9 expression in 92 tumors $(61.74 \%)$ (Figure 1).
Table I. The relationship between Krüppel-like factor 9 (KLF9) expression and clinicopathological parameters in patients with pancreatic ductal adenocarcinoma $(n=149)$.

\begin{tabular}{|c|c|c|c|c|}
\hline \multirow[t]{2}{*}{ Characteristic } & \multirow{2}{*}{$\begin{array}{l}\text { No. of } \\
\text { patients }\end{array}$} & \multicolumn{2}{|c|}{ KLF9 expression } & \multirow[t]{2}{*}{$p$-Value* } \\
\hline & & High & Low & \\
\hline \multicolumn{5}{|l|}{ Gender } \\
\hline Male & 86 & 33 & 53 & \multirow[t]{2}{*}{0.555} \\
\hline Female & 63 & 24 & 39 & \\
\hline \multicolumn{5}{|l|}{ Age } \\
\hline$<60$ Years & 71 & 28 & 43 & \multirow[t]{2}{*}{0.866} \\
\hline$\geq 60$ Years & 78 & 29 & 49 & \\
\hline \multicolumn{5}{|l|}{ Tumor position } \\
\hline Head and neck & 112 & 38 & 74 & \multirow[t]{2}{*}{0.081} \\
\hline Body and tail & 37 & 19 & 18 & \\
\hline \multicolumn{5}{|l|}{ Differentiation } \\
\hline Well & 5 & 4 & 1 & \multirow[t]{3}{*}{0.036} \\
\hline Moderately & 105 & 43 & 62 & \\
\hline Poorly & 39 & 10 & 29 & \\
\hline \multicolumn{5}{|l|}{ T-Stage } \\
\hline I & 37 & 16 & 21 & \multirow[t]{3}{*}{0.756} \\
\hline II & 89 & 33 & 56 & \\
\hline III & 23 & 8 & 15 & \\
\hline \multicolumn{5}{|l|}{ TNM stage } \\
\hline I & 29 & 14 & 15 & \multirow[t]{3}{*}{0.397} \\
\hline II & 60 & 23 & 37 & \\
\hline III & 60 & 20 & 40 & \\
\hline \multicolumn{5}{|l|}{ Perineural invasion } \\
\hline Absent & 37 & 11 & 26 & \multirow[t]{2}{*}{0.274} \\
\hline Present & 112 & 46 & 66 & \\
\hline \multicolumn{5}{|l|}{ Vascular invasion } \\
\hline Absent & 132 & 55 & 77 & \multirow[t]{2}{*}{0.017} \\
\hline Present & 17 & 2 & 15 & \\
\hline \multicolumn{5}{|l|}{ LN metastasis } \\
\hline Absent & 89 & 37 & 52 & \multirow[t]{2}{*}{0.390} \\
\hline Present & 60 & 20 & 40 & \\
\hline
\end{tabular}

TNM: Tumor-node-metastasis; LN: lymph node. *Chi-square test; significant values are shown in bold.

The relationship between KLF9 expression and clinicopathological variable is summarized in Table I. The KLF9 expression level did not significantly differ according to gender, age, tumor position, T-stage, TNM stage, perineural invasion or lymph node metastasis. Low KLF9 expression was significantly associated with poor differentiation and vascular invasion ( $p=0.036$ and $p=0.017$, respectively).

Prognostic value of KLF9 expression in PDAC. Overall survival by Kaplan-Meier curves based on KLF9 expression are shown in Figure 2. Patients with low KLF9 expression had a poorer OS (17.9\%) than those with high KLF9 expression $(24.1 \%) \quad(p=0.001)$. In addition to KLF9 expression, univariate analysis demonstrated that differentiation, TNM stage, perineural invasion, lymph node 
A

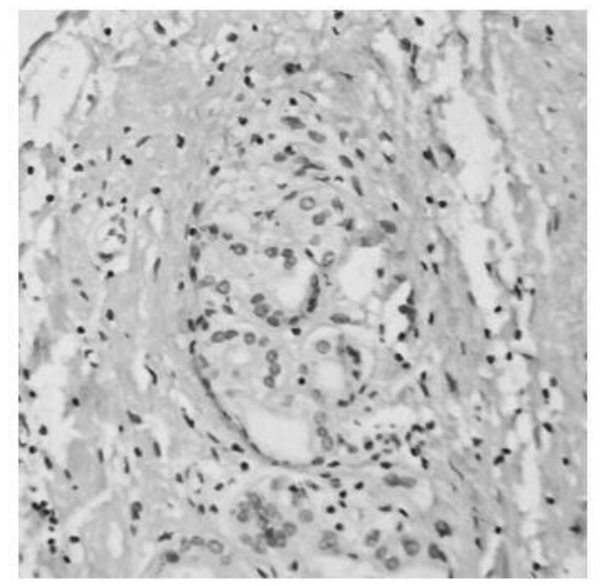

C

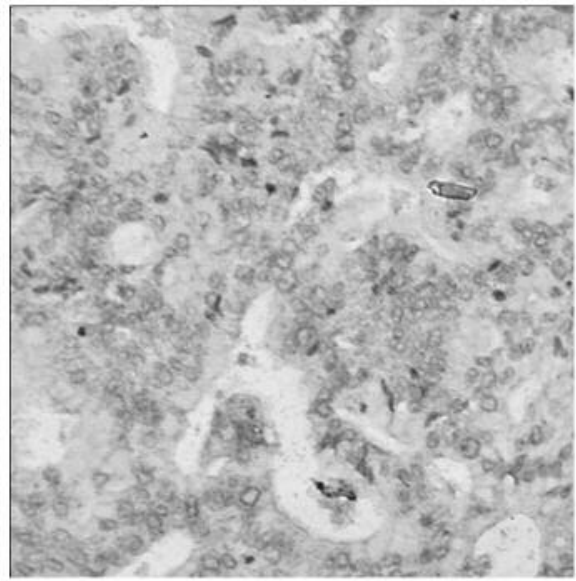

B

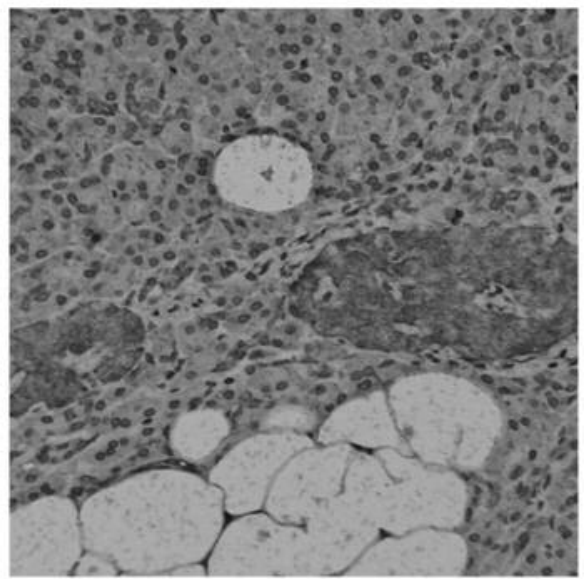

D

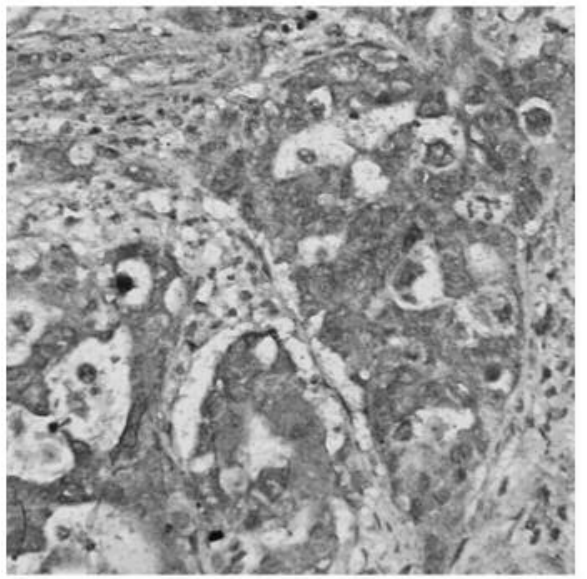

Figure 1. Immunostaining of Krüppel-like factor 9 (KLF9) in human pancreatic ductal adenocarcinoma (magnification, $\times 400)$. A: Negative control; B: normal tissue; C: low KLF9 expression; D: high KLF9 expression.

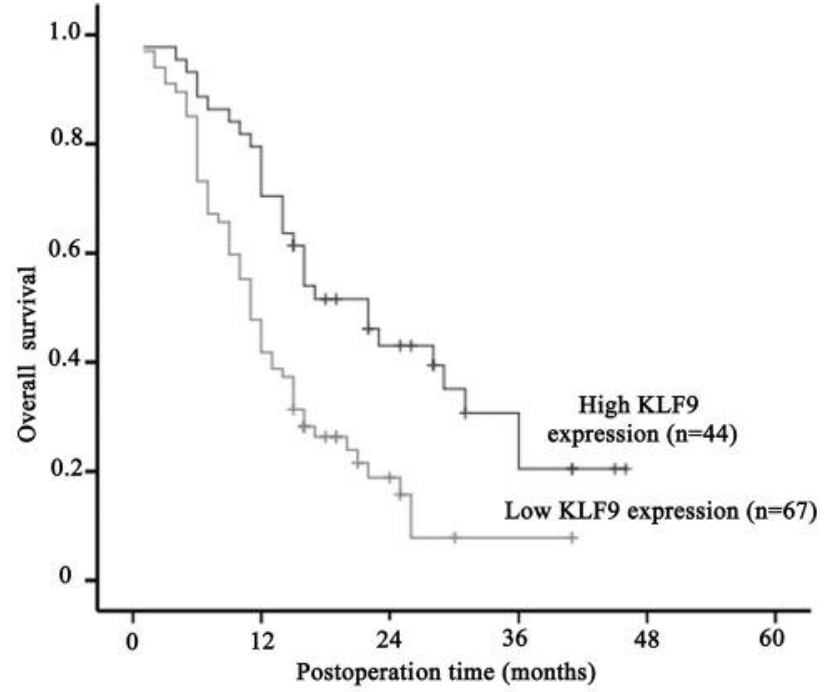

Figure 2. Overall survival curves of patients with pancreatic ductal adenocarcinoma according to Krüppel-like factor 9 (KLF9) expression. Patients with high expression of KLF9 had a significantly better survival rate than patients with low KLF9 expression $(p=0.001)$.

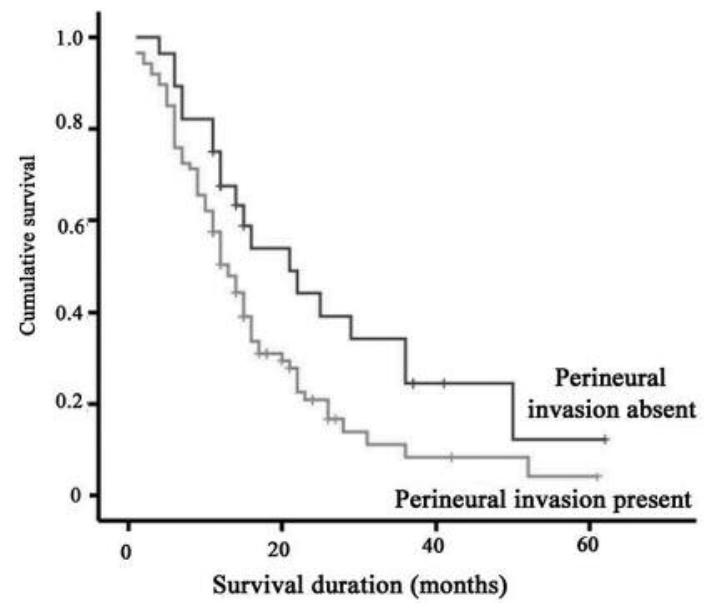

Figure 3. Overall survival curves of patients with pancreatic ductal adenocarcinoma with perineural invasion. Patients with perineural invasion had a significantly poor survival rate than patients without $(p=0.011)$. 
Table II. Univariate hazard ratio analysis of prognostic factors after pancreatic resection in patients with pancreatic ductal adenocarcinoma $(n=111)$.

\begin{tabular}{|c|c|c|c|c|}
\hline Variable & No. & HR & $95 \% \mathrm{CI}$ & $p$-Value \\
\hline \multicolumn{5}{|l|}{ Gender } \\
\hline Male & 62 & 1.091 & $0.709-1.677$ & 0.692 \\
\hline Female & 49 & & & \\
\hline \multicolumn{5}{|l|}{ Age } \\
\hline$<60$ Years & 47 & 1.005 & $0.985-1.026$ & 0.625 \\
\hline$\geq 60$ Years & 64 & & & \\
\hline \multicolumn{5}{|l|}{ Tumor position } \\
\hline Head and neck & 85 & 0.652 & $0.382-1.112$ & 0.116 \\
\hline Body and tail & 26 & & & \\
\hline \multicolumn{5}{|l|}{ Differentiation } \\
\hline Well & 5 & 1.486 & $1.006-2.197$ & 0.047 \\
\hline Moderately & 69 & & & \\
\hline Poorly & 37 & & & \\
\hline T-Stage & & 1.037 & $0.744-1.445$ & 0.831 \\
\hline I+II & 93 & & & \\
\hline III+IV & 18 & & & \\
\hline TNM stage & & 1.560 & $1.136-2.141$ & 0.006 \\
\hline $\mathrm{I}+\mathrm{II}$ & 64 & & & \\
\hline III+IV & 47 & & & \\
\hline Perineural invasion & & 2.099 & $1.149-3.834$ & 0.016 \\
\hline Absent & 24 & & & \\
\hline Present & 87 & & & \\
\hline Vascular invasion & & 1.145 & $0.704-2.847$ & 0.330 \\
\hline Absent & 100 & & & \\
\hline Present & 11 & & & \\
\hline LN metastasis & & 2.1 & $1.360-3.241$ & 0.001 \\
\hline Absent & 64 & & & \\
\hline Present & 47 & & & \\
\hline KLF9 expression & & 2.190 & $1.373-3.494$ & 0.001 \\
\hline Absent & 67 & & & \\
\hline Present & 44 & & & \\
\hline
\end{tabular}

HR: Hazard ratio; CI: confidence interval; TNM: tumor-nodemetastasis; LN: lymph node; KLF9: Krüppel-like factor 9. Significant values are shown in bold.

metastasis were also significantly associated with OS, while others were not (Table II).

In order to obtain a more precise estimate, multivariate analysis was performed to identify the independent prognostic factors. Using multivariate analysis, low KLF9 expression was confirmed as an independent prognostic factor for pancreatic ductal adenocarcinoma $(p=0.0002$, Table III), suggesting that poor expression of KLF9 was a high-risk factor for poor prognosis. Furthermore, perineural invasion $(p=0.005)$ also remained an independent prognostic indicator and the mean survival of patients with perineural invasion was $16.14 \pm 1.34$ months versus $26.79 \pm 3.46$ months for those without ( $p=0.011$, Figure 3 ), while differentiation, TNM stage and LN metastasis lost significance.
Table III. Multivariate hazard ratio analysis of prognostic factors after pancreatic resection in patients with pancreatic ductal adenocarcinoma $(n=111)$.

\begin{tabular}{lrccc}
\hline Variable & No. & HR & $95 \%$ CI & $p$-Value \\
\hline $\begin{array}{l}\text { Differentiation } \\
\quad \text { Well }\end{array}$ & 5 & 1.388 & $0.949-2.029$ & 0.091 \\
$\quad$ Moderately & 69 & & & \\
$\quad$ Poorly & 37 & & & \\
TNM stage & & & & \\
$\quad$ I+II & 64 & 1.177 & $0.609-2.274$ & 0.628 \\
$\quad$ III+IV & 47 & & & \\
Perineural invasion & & & & \\
$\quad$ Absent & 24 & 2.435 & $1.311-4.521$ & $\mathbf{0 . 0 0 5}$ \\
$\quad$ Present & 87 & & & \\
LN metastasis & & & & \\
$\quad$ Absent & 64 & 1.628 & $0.616-4.303$ & 0.326 \\
$\quad$ Present & 47 & & & \\
KLF9 expression & & & & \\
$\quad$ Absent & 67 & 2.470 & $1.536-3.971$ & $\mathbf{0 . 0 0 0 2}$ \\
$\quad$ Present & 44 & & & \\
\hline
\end{tabular}

HR: Hazard ratio; CI: confidence interval; TNM: tumor-nodemetastasis; LN: lymph node; KLF9: Krüppel-like factor 9. Significant values are shown in bold.

\section{Discussion}

In present study, by comparing the clinical parameters of patients, it was found that KLF9 status was only associated with differentiation and vascular invasion. This may be related to the function of KLF9 during carcinogenesis. KLF9 induced glioma neurosphere cell differentiation, inhibited neurosphere formation, and inhibited neurospherederived xenograft growth in vivo through binding with the promoter of NOTCH1 (14). KLF9 also promoted the differentiation of dental follicle cells in vitro (15). In pericyte-like cell differentiation of glioblastoma stem cells, KLF9 induced a vascularization switch with NOTCH1 stimulation (16).

Furthermore, we demonstrated that patients whose nuclei of pancreatic cancer cells were negative for KLF9 had a mean survival of $14.17 \pm 1.39$ months compared to $23.95 \pm 2.32$ months for those whose cells expressed KLF9. The results imply that low KLF9 expression in pancreatic ductal adenocarcinoma may be considered an indicator of poor prognosis in patients who underwent radical resection with curative surgery.

In the multivariable models, KLF9 was confirmed as an independent prognostic factor. Our assessment of KLF9 applied to patients with PDAC who underwent radical surgery. But whether KLF9 status is important in patients with carcinoma of only the pancreatic head or with pancreatic body and tail carcinoma, or with unresectable disease remains unknown. 
In our present study, the number of patients recruited was inadequate and there is a possibility of bias. The majority of our cases had PDAC in the pancreatic head. If possible, we would include more patients with PDAC in the body and tail of the pancreas and examine the difference of KLF9 expression pattern. Due to the insidious nature of PDAC, most patients initially presenting with symptoms are diagnosed with locally advanced tumor stage; patients with TNM I stage are very rare. This may have had an underlying effect on the present study. In future studies, it is necessary to include more patients with early-stage disease. However, in the multivariable Cox proportional hazards models, the analyses strongly imply that nuclear KLF9 expression may be a useful biomarker of outcome in patients with PDAC.

The mechanism by which low KLF9 expression portends a worse prognosis is not fully known. Former studies demonstrated that KLF9 induced apoptosis through dysregulation of p53 and programmed cell death protein 5 (PDCD5) (8). Furthermore, KLF9 inhibited the migration and proliferation of cancer stem cells $(4,16)$. Interestingly, recent studies found that KLF9 inhibited the WNT/ $\beta$-catenin signaling through binding with transcription factor 4 (17).

In summary, low nuclear KLF9 expression is a marker of poor prognosis in patients with PDAC, independently of common clinical parameters including TNM stage, perineural invasion, and lymph node metastasis. The mechanisms that confer this malignant phenotype need additional study.

\section{Acknowledgements}

This work was sponsored by the National Natural Science foundation of China, Grant numbers: 81502372; Natural Science Foundation of Jiangsu Province (Youth Fund), Grant numbers: BK20130475; Jiangsu Provincial Medical Youth Talent (QNRC2016838， QNRC2016839); Zhenjiang Science and Technology Pillar Program, Grant numbers: SH2014035; The Foundation for Young Scientists of affiliated Hospital of Jiangsu University (Grant numbers: JDFYRC2013009, JDFYRC2016002).

\section{References}

1 Siegel RL, Miller KD and Jemal A: Cancer statistics, 2016. CA Cancer J Clin 66: 7-30, 2016.

2 Wolfgang CL, Herman JM, Laheru DA, Klein AP, Erdek MA, Fishman EK and Hruban RH: Recent progress in pancreatic cancer. CA Cancer J Clin 63: 318-348, 2013.

3 Kang L and Lai MD: $B T E B / K L F 9$ and its transcriptional regulation. Yi Chuan 29: 515-522, 2007.

4 Ying M, Tilghman J, Wei Y, Guerrero-Cazares H, QuinonesHinojosa A, Ji H and Laterra J: Kruppel-like factor-9 (KLF9) inhibits glioblastoma stemness through global transcription repression and integrin alpha6 inhibition. J Biol Chem 289: 32742-32756, 2014.

5 Huang S, Wang C, Yi Y, Sun X, Luo M, Zhou Z, Li J, Cai Y, Jiang $\mathrm{X}$ and $\mathrm{Ke} \mathrm{Y}$ : Kruppel-like factor 9 inhibits glioma cell proliferation and tumorigenicity via down-regulation of miR-21. Cancer Lett 356: 547-555, 2015.
6 Limame R, de Beeck KO, Van Laere S, Croes L, De Wilde A, Dirix L, Van Camp G, Peeters M, De Wever O, Lardon F and Pauwels P: Expression profiling of migrated and invaded breast cancer cells predicts early metastatic relapse and reveals Kruppel-like factor 9 as a potential suppressor of invasive growth in breast cancer. Oncoscience 1: 69-81, 2014.

7 Brown AR, Simmen RC, Raj VR, Van TT, MacLeod SL and Simmen FA: Kruppel-like factor 9 (KLF9) prevents colorectal cancer through inhibition of interferon-related signaling. Carcinogenesis 36: 946-955, 2015.

8 Fu DZ, Cheng Y, He H, Liu HY and Liu YF: The fate of Kruppellike factor 9-positive hepatic carcinoma cells may be determined by the programmed cell death protein 5. Int J Oncol 44: 153-160, 2014.

9 Zhang QH, Dou HT, Tang YJ, Su S and Liu PS: Lentivirusmediated knockdown of Kruppel-like factor 9 inhibits the growth of ovarian cancer. Arch Gynecol Obstet 291: 377-382, 2015.

10 Sun ZJ, Wang Y, Cai Z, Chen PP, Tong XJ and Xie D: Involvement of Cyr61 in growth, migration, and metastasis of prostate cancer cells. Br J Cancer 99: 1656-1667, 2008.

11 Deng YZ, Yao F, Li JJ, Mao ZF, Hu PT, Long LY, Li G, Ji XD, Shi S, Guan DX, Feng YY, Cui L, Li DS, Liu Y, Du X, Guo MZ, Xu LY, Li EM, Wang HY and Xie D: RACK1 suppresses gastric tumorigenesis by stabilizing the beta-catenin destruction complex. Gastroenterology 142: 812-823e815, 2012.

12 Chen YT, Huang ZP, Zhou ZW and He MM: Equipping the American Joint Committee on Cancer staging for resectable pancreatic ductal adenocarcinoma with tumor grade: a recursive partitioning analysis. Med Oncol 33: 122, 2016.

13 Yang M, Ke NW, Zeng L, Zhang Y, Tan CL, Zhang H, Mai G, Tian BL and Liu XB: Survival Analyses for Patients With Surgically Resected Pancreatic Neuroendocrine Tumors by World Health Organization 2010 Grading Classifications and American Joint Committee on Cancer 2010 Staging Systems. Medicine 94: e2156, 2015.

14 Ying M, Sang Y, Li Y, Guerrero-Cazares H, Quinones-Hinojosa A, Vescovi AL, Eberhart CG, Xia S and Laterra J: Kruppel-like family of transcription factor 9 , a differentiation-associated transcription factor, suppresses Notch1 signaling and inhibits glioblastoma-initiating stem cells. Stem Cells 29: 20-31, 2011.

15 Morsczeck C, Schmalz G, Reichert TE, Vollner F, Saugspier M, Viale-Bouroncle S and Driemel O: Gene expression profiles of dental follicle cells before and after osteogenic differentiation in vitro. Clin Oral Investig 13: 383-391, 2009.

16 Guichet PO, Guelfi S, Teigell M, Hoppe L, Bakalara N, Bauchet L, Duffau H, Lamszus K, Rothhut B and Hugnot JP: Notch1 stimulation induces a vascularization switch with pericyte-like cell differentiation of glioblastoma stem cells. Stem Cells 33: 21-34, 2015.

17 Qiao F, Yao F, Chen L, Lu C, Ni Y, Fang W and Jin H: Kruppellike factor 9 was down-regulated in esophageal squamous cell carcinoma and negatively regulated beta-catenin/TCF signaling. Mol Carcinog 55: 280-291, 2016.
Received May 20, 2017

Revised June 3, 2017

Accepted June 7, 2017 